\title{
O AMOR COMO FUNDAMENTO ONTOLÓGICO DA ORDEM EM SANTO AGOSTINHO
}

\author{
FRANCISCO CLEBIO FIGUEIREDO ${ }^{1}$ \\ $\mathbf{E}$ \\ FRANCISCO ROMÁRIO DE QUEIROZ SILVA ${ }^{2}$
}

RESUMO: Considerando a relevância que os termos ordem e amor possuem na doutrina de Santo Agostinho, objetiva-se apresentar como o amor constitui-se o fundamento ontológico da ordem nos escritos agostinianos. Para tanto, procede-se a um estudo da teoria dos dois amores e das duas cidades, bem como a uma investigação do conceito de ordem em Santo Agostinho. Desse modo, observa-se que o amor é um impulso que move a vontade do homem a um determinado objeto e, por sua vez, é a origem e o princípio das duas cidades. O amor será reto se, obedecendo à ordem hierárquica dos seres, tender ao que há de mais elevado, de modo que o indivíduo ascenda ao inteligível. Por outra via, o amor será desordenado se o homem, não distinguindo os seres superiores dos inferiores, optar por usar o que se deve fruir e fruir do que deve ser utilizado. Enquanto o amor unicamente a si é a origem mesma da desordem, o amor desprendido e devotado a Deus e ao próximo é o fundamento da comunhão. O que permite concluir que o amor constitui o fundamento da ordem na ontologia de Santo Agostinho.

PALAVRAS-CHAVE: Ordem, Amor, Ontologia, Cidade.

ABSTRACT: Considering the relevance that the terms order and love have in the doctrine of Saint Augustine, the objective is to present how love constitutes the ontological foundation of order in Augustinian writings. To this end, we proceed to a study of the theory of two loves and of two cities, as well as an investigation of the concept of order in Saint Augustine. Thus, it is observed that love is an impulse that moves the will of man to a certain object and, in turn, it is the origin and principle of the two cities. Love will be right if, obeying the hierarchical order of beings, it tends to the highest, so that the individual ascends to the intelligible. In another way, love will be disordered if man, not distinguishing between superior and inferior beings, chooses to use what is to be enjoyed and what is to be used. While love for itself alone is the source of disorder, love that is detached and devoted to God and neighbor is the foundation of communion. It allows us to conclude that love is the foundation of order in Saint Augustine's ontology.

KEYWORDS: Order. Love. Ontology. City.

\footnotetext{
${ }^{1}$ Professor da Faculdade Evolução Alto Oeste Potiguar (FACEP) nos cursos de Pedagogia e Administração. Professor substituto na Universidade do Estado do Rio Grande do Norte (UERN). Doutorando em Letras pelo Programa de Pós-graduação em Letras da Universidade do Estado do Rio Grande do Norte (UERN). E-mail: clebiofigueiredo@uern.br.

${ }^{2}$ Graduando do curso de Letras Língua Portuguesa pela Universidade do Estado do Rio Grande do Norte (UERN). E-mail: romario15frr@gmail.com.
} 
A natureza do amor e da ordem são temas bastante discutidos na filosofia agostiniana. Nos seus primeiros diálogos filosóficos, como o De ordine, Agostinho já refletia sobre a disposição precisa a que os elementos da criação obedecem. Todo objeto é constituído de medida, número e peso. Esses atributos ontológicos constituem a natureza das coisas criadas e determinam seu lugar no universo e na hierarquia dos seres.

O princípio da ordem estabelece o fundamento e a harmonia da criação. Sem essa ordenação, o universo, tal como é concebido por Santo Agostinho, estaria num caos e numa profunda confusão. Cada ser possuí seu lugar específico no cosmos agostiniano: há os bens inferiores, os bens medianos e os bens superiores. Enquanto, de um lado, Agostinho classifica todos os objetos como necessariamente bons, por outro, eles não o são num mesmo grau. Cabe ao homem, apreciador desses bens, discernir entre aqueles que são superiores e os inferiores, de modo a tender sempre ao inteligível.

Há no homem um impulso ou desejo intenso que o move ao encontro daquilo que ele deseja: isso é o amor. É ele um fator determinante no homem, é o impulso que o move à obediência ou deserção dessa ordem das coisas. Se o amor move o homem, este tenderá à ordem ou à desordem mediante o amor que houver nele. Desse modo, objetiva-se neste artigo apresentar como o amor, na filosofia agostiniana, se constitui como fundamento ontológico da ordem.

Para tanto, procedeu-se à seleção de quatro textos principais nos quais Santo Agostinho dedicou-se à definição de sua teoria dos dois amores e das duas cidades, estando eles nas obras A verdadeira religião, Primeira catequese aos não cristãs, A cidade de Deus e o Comentário Literal ao Gênesis. Numa primeira parte se mostra o contexto histórico no qual Agostinho escreveu a De civitate Dei e a sua teoria dos dois amores e das duas cidades. Para o aporte teórico da pesquisa, além dos textos de Santo Agostinho, buscou-se pesquisadores das obras do bispo de Hipona como Gilson (2010) e Trapé (2018).

Observou-se que a teoria das duas cidades, prenunciada em A verdadeira religião, desenvolvida e levada a termo em A cidade de Deus, pareceu apresentar um problema em suas considerações: como conciliar o amor a si e o amor a Deus, ou em outro sentido, o amor próprio e o amor ao próximo, uma vez que nesta última obra o amor a si é a raiz e o princípio da cidade terrena e, por conseguinte, das guerras, ódio e desunião.

Por esta razão, numa segunda parte procurou-se demonstrar como se constrói e se organiza o cosmos agostiniano, entendido a partir de um viés cristão, no qual tudo o que existe foi criado pelo Deus bíblico. Por ser obra desse Deus, todas as coisas são boas. Entretanto, há 
entre as coisas umas que se devem amar por si mesmas, pois constituem o Sumo bem, e as que devem ser amadas e usadas somente em vista a levar o homem a aderir a esse Bem.

Desse modo, com base na obra A doutrina cristã e o quarto e último texto que se selecionou das obras de Agostinho em que ele trata da origem e desenvolvimento das duas cidades, tentou-se demonstrar que o Doutor de Hippo não defende que não se deva amar o homem, mas que esse amor deve estar abaixo do amor que é devido ao Sumo Bem, e deve pressupor a comunhão com o próximo.

\section{Os dois amores e as duas cidades}

Em 410 a cidade de Roma foi invadida e saqueada pelos godos, liderados por Alarico. O episódio causou grande angústia na população, dada a ideia de Roma ser a Cidade Eterna. Pensar em uma possível queda do Império seria um enorme disparate para uma época em que os romanos estendiam sua dominação sobre a maioria das regiões circunvizinhas. A glória de Roma, e a imposição de sua força e poderio, era o princípio de segurança e conforto da população. Pensar numa dissolução da Pax Romana seria loucura.

Entretanto, com a invasão de Alarico, os ânimos mudaram, e passou-se a perceber uma ruína e guerra próximas. Vendo as devastações presentes e as angústias que estavam por vir, a massa popular, tendo em vista achar os culpados por tal situação, não tardou a responsabilizar os cristãos.

A julgar pela ótica religiosa ainda reinante, não é de se estranhar que tenham culpado os cristãos. O paganismo, comparando-se com o que foi outrora, estava agora já quase extinto, devido à grande propagação do cristianismo e sua instituição como religião oficial do Estado. Apesar da tentativa de ressurreição do paganismo por parte do Imperador Juliano, o Apóstata, este já estava, como diz Rops (1998), experimentando seus dias de agonia. Desse modo, os pagãos argumentavam que, tendo o cristianismo substituído o paganismo como religião oficial, Roma já não contava com a proteção dos deuses, razão pela qual estava agora sendo cercada e pilhada.

Em meio a esse contexto, Santo Agostinho decidiu escrever uma de suas principais obras, A cidade de Deus, tendo em vista defender a Igreja Católica das acusações de estar levando o Império à ruína, como ele próprio o diz nas suas Retratações:

Nesse ínterim, Roma foi arrasada pela invasão dos godos, comandados por Alarico, e pela violência de uma grande calamidade. Os adoradores dos falsos e muitos deuses, que denominamos pelo nome mais vulgar de pagãos, empenhando-se em atribuir o fato à religião cristã, começaram a blasfemar violenta e rancorosamente contra o Deus 
verdadeiro. Por isso, inflamado pelo zelo pela casa de Deus, decidi escrever os livros de $A$ cidade de Deus contra suas blasfêmias e erros (SANTO AGOSTINHO, 2019, p. 159-160).

Empenhando-se em refutar estas acusações contra o cristianismo, como bem afirma Leão (2013), ele desenvolve em A cidade de Deus a primeira filosofia cristã da história. Esta é reinterpretada pala ótica do cristianismo a partir dos escritos bíblicos, em vista a demonstrar que as catástrofes pelas quais Roma é agora atingida não são diferentes das que ocorreram no passado. Outrossim, nos primeiros livros da obra, o bispo de Hipona reconstrói o passado de Roma, demonstrando a partir de fatos históricos e dos próprios historiadores romanos que, antes do cristianismo, Roma passou por dificuldades bem maiores, sem receber auxílio de qualquer um de seus deuses. Por outro lado, Agostinho disserta que, em respeito aos templos sagrados e ao Deus bíblico, os reis bárbaros se mostraram benevolentes e misericordiosos com os romanos (Cf. SANTO AGOSTINHO, 2013, p. 31).

Para o desenvolvimento do seu projeto, Agostinho divide, então, a história da humanidade em duas cidades, as quais se remontam a dois homens, e esses, por sua vez, remetem a dois amores, princípios que caracterizam e conceituam ambas as cidades em relação à sua origem, seu objeto de busca e seus fins.

Embora seja em A cidade de Deus que Santo Agostinho desenvolve de uma maneira ampla sua teoria das duas cidades, ela já havia sido apontada em outras obras, bem como em seus sermões ao povo. Além da obra já citada, pode-se apontar outros três textos considerados como fundamentais para a compreensão da teoria agostiniana, os que estão nas obras $A$ verdadeira religião, a Primeira catequese aos não cristãos e o Comentário literal ao Gênesis. Todavia, esse último será tratado mais adiante.

Agostinho escreveu A verdadeira religião quando ainda era leigo, no ano 390, entre sua conversão ao cristianismo e sua ordenação sacerdotal, com o objetivo de "atrair ao catolicismo o influente Romaniano, um de seus melhores amigos" (FRANGIOTTI; OLIVEIRA, 2002, p, 17), o qual era membro da seita maniqueísta. Nesta que é, portanto, obra de sua juventude, ele disserta que todo o gênero humano remonta a Adão e, assim, constitui uma unidade que liga todos os homens. Por sua vez, considerando juntos o Antigo e o Novo Testamento, ele explica que a história do gênero humano, desde Adão até os últimos dias, se divide em dois grandes conjuntos de povos. Eis o texto:

Pelas leis da divina Providência que a governa, aparece a humanidade distribuída em duas classes. Uma constituída pela multidão dos ímpios que trazem impressa a imagem do homem terreno desde o início dos tempos até o seu fim. A outra classe é 
formada das gerações de um povo consagrado ao único Deus. De Adão a João Batista, conduziu Deus a vida do homem terreno sob certa justiça servil. Sua história chamase o Antigo Testamento, sob a promessa de um reino temporal. Mas toda essa história, no seu conjunto, nada mais é do que a imagem do novo povo do Novo Testamento, ao qual é prometido o reino dos céus. A vida desse povo, na fase temporal, vai da vinda do Senhor à humildade, até a sua volta à glória, no dia do Juízo (SANTO AGOSTINHO, 2002, p. 53).

Neste texto, Agostinho já pressupõe sua teoria das duas cidades, com a denominação aqui de duas classes. Como fator distintivo de ambas, o bispo de Hipona usa a imagem paulina do "homem velho e o novo" que, por sua vez, remete ao batismo cristão e a uma vida de retidão moral. Na Primeira catequese aos não cristãos esses dois povos convertem-se em duas cidades. Estas, por sua vez, na vida presente percorrem juntas a história e são indistintas segundo seu aspecto físico. Segundo Agostinho, o princípio de identificação de ambas é tão somente no nível espiritual, ou seja, no tocante à fé e à caridade. Nas palavras de Maschio (2015, p. 113), “apesar de serem materialmente indistinguíveis, para Santo Agostinho é possível caracterizar cada uma delas por meio da contraposição de três eixos diferenciadores: o princípio que as rege, a orientação de sua vontade e o perfil dos seus habitantes". Eis como Agostinho as descreve na Primeira catequese aos não cristãos:

Duas cidades, uma dos iníquos, a outra dos justos continuam seu caminho desde o princípio do gênero humano até o fim do mundo; no presente estão mescladas segundo o corpo, mas distintas segundo o espírito; no futuro, no dia do juízo, serão separadas também segundo o corpo. De fato, todos os homens que amam a soberba e o domínio temporal [...] e buscam a própria glória no subjugar os outros estão reunidos numa mesma sociedade [...]. Ao contrário, todos os homens e os espíritos que buscam humildemente a glória de Deus e não a própria e servem a Deus com piedade, pertencem todos, também esses, a uma mesma sociedade (SANTO AGOSTINHO, Apoud TRAPÉ, 2018, p. 356-357).

Nesta obra transparece já o sistema que Agostinho levará a cabo em A cidade de Deus. $\mathrm{Na}$ verdade, os termos, as origens e os fins de ambas as cidades presentes neste texto são quase os mesmos que ele empregará mais tarde. Uma noção que falta a esse segundo texto citado e que será cara na filosofia agostiniana, principalmente na terminologia das duas sociedades, é a noção de amor. Entretanto, está sugerida nas paixões que impulsionam os cidadãos de uma e outra cidade: os que buscam a própria glória e os que buscam a glória de Deus. Posteriormente, Agostinho precisará melhor essas antíteses e acrescentará a noção dos dois amores.

Enfim, no livro XIV de A Cidade de Deus, o Doutor de Hippo precisa e conclui sua doutrina. Aí, ambas as cidades se originam de dois amores distintos: um voltado inteiramente para si, de tal forma que exclui os demais de sua comunhão, é, portanto, um egoísmo extremo e fechado em si mesmo; o outro, doa-se de tal modo que se desprende de si para ir ao encontro 
do outro, produz unidade e relação. O primeiro produz a afinidade e o segundo, a desarmonia. Ambos movem a vontade humana que, por sua vez, é todo movimento da alma em direção a um dado objeto. Portanto, toda a ação desempenhada pelo homem é feita pela vontade, sendo esta movida por um ou por outro amor. Eis o texto:

\begin{abstract}
Dois amores fundaram, pois, duas cidades, a saber: o amor próprio, levado ao desprezo de Deus, a terrena; o amor a Deus, levado ao desprezo de si próprio, a celestial. Gloria-se a primeira em si mesma e a segunda em Deus, porque aquela busca a glória dos homens e tem esta por máxima a glória de Deus, testemunha de sua consciência. Aquela ensoberbe-se em sua glória e esta diz a seu Deus: Sois minha glória e quem exalta minha cabeça. Naquelas, seus príncipes e as nações avassaladas veem-se sob o jugo da concupiscência de domínio; nesta, servem em mútua caridade, os governantes, aconselhando, e os súditos obedecendo. Aquela ama sua própria força em seus potentados; e esta diz a seu Deus: A ti hei de amar-te, Senhor, que és minha fortaleza (SANTO AGOSTINHO, 2012, p. 204).
\end{abstract}

Contudo, esse texto levanta um problema: pode haver uma oposição entre o amor a si e o amor a Deus? Nos textos bíblicos o amor que se deve tributar ao próximo é equiparado ao amor que se deve ter a si próprio. Por sua vez, esse, juntamente com o amor que se deve tributar a Deus, constitui-se como a regra fundamental de conduta moral para o cristianismo ${ }^{3}$.

Nos escritos joaninos, o amor ao próximo é pré-requisito para se chegar a conhecer e amar a Deus (Jo 4, 20-21). Desse modo, ambos os amores se associam e convergem para um mesmo fim. Entretanto, no texto acima citado, Agostinho parece separá-los e direcioná-los a fins divergentes. Como conciliar isso? Certamente o Doutor da Graça não estaria propagandeando uma heresia, tão preocupado que foi, após sua conversão, em ensinar e professar a doutrina católica em sua totalidade. Ao mesmo tempo, não há qualquer censura ao pensamento agostiniano pelas autoridades eclesiásticas, sobretudo, no tocante à De civitate Dei Há, portanto, que se buscar uma outra resposta ao problema.

$\mathrm{Na}$ verdade, o próprio Agostinho se preocupou em dar a resposta, em outras de suas obras, a essa indagação. Comentando esse texto de A cidade de Deus, Trapé (2018, p. 358) propõe esse problema e apresenta de que modo ele interessou e foi estudado pelo próprio Agostinho:

Há neste texto, justamente célebre, o fundamento e o projeto das duas cidades. Mas ele põe um grande problema. Como há oposição entre o amor a si e o amor a Deus, se é verdade que só o amor a Deus é autêntico amor a si? Essa oposição tem algo de misterioso. Agostinho fala disso seguidamente ao povo. Em seus escritos, encontramos duas séries de textos: um que coloca em relevo, como o texto citado, a oposição; outra que sublinha a feliz e necessária coincidência: "Não sei de que modo

\footnotetext{
${ }^{3}$ Sobretudo Mateus 22, 37-39.
} 
inexplicável acontece que quem ama a si mesmo, e não a Deus, não ama a si mesmo, enquanto quem ama a Deus, e não a si mesmo, este ama a si mesmo".

Neste texto de Agostinho citado por Trapé, retirado da obra Comentário ao Evangelho de João, o Doutor de Hippo já aponta uma possível solução: amar a Deus implica amar também a si próprio, enquanto amar somente a si parece excluir a Deus desse amor e ao próximo também. Talvez, tendo por base uma outra doutrina cara ao bispo de Hipona, possa-se compreender e solucionar esse problema contrastante do amor a si e o amor a Deus. Trata-se de sua doutrina sobre a ordem do universo.

Agostinho sempre considerou que o universo foi de tal modo formado por seu criador, que o foi de um modo perfeitamente ordenado. Em A Trindade, ele afirma que todo o cosmos possui uma medida, número e peso (SANTO AGOSTINHO, 1995, p. 129). Esses três atributos ontológicos constituem a essência de todo e qualquer objeto, pelos quais cada coisa, em sua natureza, é constituída boa. No diálogo A ordem, o bispo de Hipona considera que até mesmo no barulho causado pela chuva há uma variabilidade de sons que dão harmonia ao todo (SANTO AGOSTINHO, 2008, p. 100).

O universo agostiniano é um todo hierarquizado e ordenado, e isto de tal modo que há uma hierarquia entre os próprios seres vivos. De fato, em O livre arbítrio, Agostinho classifica os seres entre aqueles que apenas existem; os que existem e vivem; os que existem, vivem e sentem; e os que existem, vivem, sentem e pensam (SANTO AGOSTINHO, 1995, p. 89). Se ele assim classifica os seres, significa que há uns superiores a outros. Logo, o amor deve estar ordenado de tal modo que não se ame o inferior com mais intensidade que o superior. Com estas palavras, Gilson (2010, p. 124) classifica a concepção da organização do universo agostiniano: "No seu universo hierarquizado, todos os seres necessariamente são superiores ou inferiores uns aos outros unicamente pelo fato de serem diferentes e, para ele, trata-se de um princípio primeiro que o inferior não pode agir sobre o superior".

Portanto, a resposta para esse problema suscitado pela teoria agostiniana - isto é, da incompatibilidade entre o amor a si e o amor a Deus - deve partir de sua concepção em torno da ordenação do universo. Uma vez que tudo no cosmos agostiniano possui seu lugar próprio, o amor também deve estar dirigido a um fim especifico que o torne reto, de modo que cada coisa seja amada conforme seu lugar na hierarquia da criação. 


\section{A ordem do amor}

A incompatibilidade entre o amor próprio e o amor a Deus suscitado pela terminologia de Santo Agostinho parece, de primeira vista, um ponto antagônico entre sua teologia e os preceitos da religião cristã. Se o homem, como afirma o livro do Gênesis, foi criado "à imagem e semelhança de Deus" (Gn 1, 26-28); ao mesmo tempo, se Deus ama toda a sua criação e se toda ela foi criada boa; como o homem, que, por ser um ser racional, está no topo da hierarquia do universo, não deve amar-se?

Uma leitura atenta dos textos agostinianos mostra que tal ideia nunca foi sustentada pelo bispo de Hipona. Há de se ter em mente que, para a compreensão dos postulados de Agostinho, deve-se proceder a uma leitura atenta do conjunto de sua produção. Por certo, seus escritos não obedecem ao conceito de sistematização com o sentido que a modernidade emprega, ou como o fez Tomás de Aquino.

Numa mesma obra, Santo Agostinho ocupa-se vários temas à medida que ele avança em suas discussões. A teoria da iluminação, por exemplo, é anunciada já nos Soliloquios, discutida em A Trindade, nas Confissões e em tantos outros de seus escritos. Desse modo, a seleção dos textos e a leitura conjunta de ambos fornecem o todo de seu pensamento e a complementaridade que um exerce sobre o outro.

Assim, também no que concerne à teoria dos dois amores, há que se buscar seus apontamentos sobre o assunto em questão, em vista de, a partir de uma visão do conjunto, tentar compreender de que modo estão relacionados e como eles se ordenam dentro do universo agostiniano.

Nas primeiras páginas de A doutrina cristã, o Doutor de Hippo elabora uma classificação das coisas existentes, distinguindo entre as que devem ser utilizadas e as que devem ser fruídas. As primeiras devem ser usadas tendo em vista direcionar o homem à contemplação do Bem Supremo. Este, por sua vez, é a única realidade que deve ser fruída. Para Santo Agostinho, o Sumo Bem é o próprio Deus. Portanto, o homem deve ordenar de tal modo as coisas que tudo o leve a aderir a esse bem e a ele contemplar.

Inverter essa ordem é, na filosofia agostiniana, incorrer num abuso e perversão entre o que deve ser usado e o que deve ser fruído: "Fruir é aderir a alguma coisa por amor a ela própria. E usar é orientar o objeto de que se faz uso para obter o objeto ao qual se ama, caso tal objeto mereça ser amado. Ao uso ilícito cabe, com maior propriedade, o nome de excesso ou abuso" (SANTO AGOSTINHO, 2002, p. 34). 
Nesta mesma obra, o autor fala de uma ordem do amor, que se caracteriza pela reta avaliação das coisas, de modo a amar mais as que são superiores e amar menos as que são inferiores, e nem tampouco amar o que não merece ser amado. O homem que faz essa distinção dentre as coisas e as avalia bem é classificado por Santo Agostinho como aquele que é justo e que vive santamente.

Por certo, nesse texto está a chave de leitura para a compreensão do problema levantado em A cidade de Deus. Ali, Agostinho diz que o amor a si próprio é o fundamento da cidade dos homens. Por outro lado, no texto de A doutrina cristã, ele afirma que todo homem deve ser amado. Contudo, estabelece o seguinte princípio: o homem deve ser amado por causa de Deus, porquanto Deus deve ser amado somente por si. Então, deve-se amar mais a Deus que a si mesmo. Eis o texto:

\begin{abstract}
Vive justa e santamente quem é perfeito avaliador das coisas. E quem as estima exatamente mantém amor ordenado. Dessa maneira, não ama o que não é digno de amor, nem deixa de amar o que merece ser amado. Nem dá primazia no amor àquilo que deve ser menos amado, nem ama com igual intensidade o que se deve amar menos ou mais, nem ama menos ou mais o que convém amar de forma idêntica. O pecador, contudo, enquanto pecador, não merece ser amado: mas todo homem, enquanto tal, deve ser amado por causa de Deus. Deus, porém, por si próprio é digno de amor. E já que Deus deve ser amado mais do que todos os homens, cada um deve amar a Deus mais do que a si próprio (SANTO AGOSTINHO, 2002, p. 46).
\end{abstract}

Por conseguinte, a censura ao amor a si próprio por parte de Santo Agostinho não se dá pelo fato apenas de o homem amar-se a si próprio, mas pelo fato de amar somente e totalmente a si mesmo. Esta dileção que mais se configura à vanglória e ao egoísmo inverte a ordem dos seres e perturba a ordem do amor.

No livro X das Confissões, Agostinho descreve esse amor como um sentimento profundo que emerge de dentro da alma, voltado somente para si mesmo, excluindo de si os demais à sua volta e o próprio Deus. Este tipo de amor não só se alegra somente por si, como também se entristece com a alegria dos outros, o que se pode, com razão, denominar inveja:

Existe dentro, bem dentro de nós, outro mal, oriundo do mesmo gênero de tentação, que faz vão todos os que se comprazem em si, ainda quando não agradam aos outros - e até lhes desagradam - ou mesmo quando nem sequer procuram agradar-lhes. Ora, os que assim se comprazem em si mesmos, desagradam-vos muito, ó meu Deus, não só quando se gloriam dos males como se fossem bens, mas sobretudo quando se gloriam de vossos bens como se fossem seus; ou quando reconhecendo-vos como provenientes de Vós, os atribuem à vossa graça, não se alegram amigavelmente de que os outros também o possuam, tendo-lhes ainda, por isso mesmo, inveja (SANTO AGOSTINHO, 2015, 286). 
Por outro lado, em A doutrina cristã, o bispo de Hipona exorta que se deve ensinar o homem a amar a si próprio. O motivo para o ensinamento é propriamente para que esse amor não se sobreponha e não se torne de tal modo autossuficiente, que ame a criatura mais que o seu criador. Igualmente, esse mesmo amor não se deve restringir apenas ao próprio indivíduo, incorrendo em exclusão em relação aos demais homens. Por certo, o homem agostiniano é um sujeito social, membro constituinte de um corpo místico que é a Eclésia, isto é, a assembleia dos cristãos que formam a Cidade de Deus, uma sociedade composta de homens que se relacionam entre si pelo vínculo do amor social que os une.

Nesta sociedade, portanto, o amor deve constituir-se como um elo que relaciona os indivíduos uns com os outros. Um sentimento ou impulso que ocasione a individualidade e a exclusão está em desacordo com a ordem da criação e não obedece à ordo amoris. Eis como se expressa Agostinho em A doutrina cristã:

É preciso, pois, ensinar ao homem a medida de seu amor, isto é, a maneira como deve amar-se a si próprio, para que esse amor lhe seja proveitoso. Duvidar de que ele se ama e deseja o próprio bem é pura demência. É preciso também ensinar ao homem como deve amar seu corpo, para que tome cuidado dele, com ordem e prudência. Porque o fato de o homem usar seu corpo e desejar conservá-lo sadio e intato é verdade bem manifesta (SANTO AGOSTINHO, 2002, 34).

A solução para o problema levando pela antítese de A cidade de Deus parece estar, portanto, em outra antítese: o amor social e o amor privado. Nas palavras de Trapé (2018, p. 358): "Para ilustrar esse enigma, pode servir um outro binômio que aprofunda o primeiro, ao qual recorre o autor da Cidade de Deus, para exprimir a antítese das duas cidades: o amor social e o amor privado". Enquanto o primeiro vai ao encontro do próximo, o segundo se fecha em si mesmo e constitui o próprio indivíduo como seu próprio deus. É daí que, para Santo Agostinho, nascem as guerras, as devastações e o ódio na humanidade.

Neste ponto, situa-se o quarto texto fundamental de Santo Agostinho sobre os dois amores e as duas cidades, acima aludido, isto é, sua obra Comentário literal ao Gênesis:

Estes dois amores, dos quais um é santo, o outro impuro, um social, o outro privado, um que olha para o bem da utilidade comum em ordem à companhia celestial, o outro, que submete o comum a seu poder por causa da dominação arrogante, um, sujeito a Deus, o outro, rival de Deus, um, tranquilo, o outro, turbulento, um, pacífico, o outro, rebelde, um que prefere a verdade às louvaminhas dos que erram, o outro, ávido de louvor de qualquer maneira, um amigável, o outro, invejoso, um que quer para o próximo o que quer para si, o outro, que quer submeter o próximo a si, um que governa o próximo para a utilidade do próximo, o outro, para a sua utilidade; estes amores existiram antes entre os anjos: um nos bons, o outro nos maus; e separam as duas cidades fundadas no gênero humano sob a admirável e inefável Providência de Deus que administra e ordena todas as coisas criadas, uma dos justos, a outra dos pecadores. 
Com a mescla das duas o mundo caminha até serem separadas no último juízo, uma, unida aos anjos bons, até conseguir a vida eterna com seu Rei; a outra, unida aos anjos maus, até ser mandada para o fogo eterno com seu rei. Se o Senhor quiser, dissertaremos, talvez, mais longamente em outra ocasião sobre estas duas cidades (SANTO AGOSTINHO, 2005, p. 240-241).

Neste texto transparece de modo claro a ideia com a qual Agostinho classifica os dois amores como social e privado. É interessante destacar que esse texto é anterior à De civitate Dei. Por certo, no final do parágrafo citado, o bispo de Hipona relata seu projeto de escrever uma obra dedicada a dissertar sobre as duas cidades. Portanto, o autor de A cidade de Deus, antes do período que a escreveu, já concebia essa distinção fundamental entre os dois amores e sobre o certo sentido do amor próprio.

Comentando esse texto do Comentário literal ao Gênesis, Trapé (2018, p. 358-369) assim se expressa:

Esta radical oposição é compreensível somente se se pensa que o amor social, quer dizer para Agostinho o amor ao bem comum, enquanto o amor privado significa o amor ao bem próprio, isto é, bem possuído ou desejado com exclusão dos outros. Por isso, aquele une, este divide, e, dividindo, gera o orgulho, a avareza, a cobiça, que são a raiz de todos males. Chama-se privado porque se fecha em si e priva quem o possui da comunhão, que é a autêntica riqueza [...].

O autor de A cidade de Deus considera que o indivíduo deve amar a si próprio e aos demais homens, bem como todo o resto da criação. Contudo, esse amor deve obedecer a uma ordem, de modo que não ame em excesso o que deve ser amado menos e ame pouco o que deve ser amado mais.

Amar a Deus e amar a si próprio não são em si mesmos princípios contrários. O amor a Deus pressupõe um amor a si mesmo, pelo fato de constituir-se um ser criado por Deus, e por isso, criado bom. Para Santo Agostinho, sendo Deus o Sumo Bem, ele só pode criar coisas boas. Logo, se todas as coisas são obras de Deus, todas as criaturas são boas. Por conseguinte, todas merecem ser amadas.

Entretanto, há coisas que são amadas por si mesmas e coisas que o são em vista a alcançar algo melhor. Em outras palavras, o que deve ser amado por si mesmo é o Sumo Bem, é o objeto mesmo da fruição; o que é amado em vista a alcançar esse sumo bem é o objeto de uso.

O amor a Deus não diminui o amor a si mesmo, antes lhe dá seu próprio fundamento, pois se as coisas podem ser usadas para aproximar o homem de Deus, o amor ao outro é o 
conhecimento mesmo de Deus e a presença de Deus entre suas criaturas. Pois quem ama, ama com amor e, no amor, está o próprio Deus.

Outrossim, amar o outro não é renegar-se ou aniquilar-se. Quando Agostinho fala do "amor a Deus, levado ao desprezo de si próprio" não alude com isso que o homem não deva amar-se ou que se considere um miserável. Agostinho convida o homem a perceber, como afirma Gilson (2010), que possuir a Deus pressupõe não carecer de mais nada; quando se fala de Deus não há como amá-lo com igualdade, aí reside a desigualdade, pois ninguém o iguala. A ele deve ser votado o amor total. Esse amor nenhuma criatura merece no mesmo grau.

Por certo, esse amor orientado é, para Agostinho, o fundamento da justiça. Por sua vez, a justiça estabelece a ordem, na qual o que é inferior se submete ao que é superior, como bem afirma Gilson (2010, p. 250): “A justiça tem como função atribuir a cada um o que lhe é devido; através dela se estabelece no homem um tipo de ordem em virtude da qual o corpo se submete à alma e a alma a Deus".

\section{Considerações finais}

Mesmo antes de sua ordenação sacerdotal, logo após sua conversão ao cristianismo, Agostinho já considerava a humanidade dividida em duas classes de homens, como se observou em A verdadeira religião que, por sua vez, assume a caracterização de duas cidades na Primeira catequese aos não cristãos. Em A cidade de Deus, essas duas cidades originam-se de dois amores contrastantes que surgem a partir de duas atitudes antagônicas: o apego somente a si e o apego aos demais, a Deus e a si próprio por causa de Deus.

O amor unicamente a si é raiz de divisões, o amor ao outro é vinculo da união. Portanto, para Santo Agostinho, o amor é o fundamento ontológico da ordem social. Sendo ele ordenado, a sociedade é estável; sendo ele desordenado, a sociedade vive no caos e na guerra. O amor é o impulso que deve orientar o homem a desejar o que é superior, a usar o que deve ser utilizado e amar o que deve ser amado.

Por outra via, o amor a si não necessariamente supõe o desprezo ao outro ou a Deus. Isso decorre do amor exagerado por si mesmo e unicamente por si. Aí já não se trata de amorpróprio, mas de egoísmo e vanglória.

O amor ordenado pressupõe o princípio de justiça que, para Santo Agostinho, trata-se de dar a cada um o que lhe é devido. O homem, como todas as demais criaturas, uma vez que são obras de Deus, é um bem. Entretanto, há na criação uma hierarquia de bens. Todos devem ser amados, mas uns em maior grau e outros em menor. 
Embora em A cidade de Deus o autor descreva o amor a si e o amor a Deus como inteiramente contrastantes, uma leitura atenta das obras agostinianas e o estudo aqui empreendido revelam que, numa melhor hipótese, o Doutor de Hippo não os entende como atos conflitantes. O conflito se origina quando, esquecendo o que é superior e eterno, o homem ama com maior intensidade o que é mutável e temporal, que deveria estar abaixo do eterno na ordem dos seres e, por conseguinte, ser amado de um modo inferior em relação ao inteligível.

Logo, para Santo Agostinho, o amor constitui o fundamento ontológico da ordem, sendo ela a própria ordenação do cosmos, bem como a própria ordem social. Distinguindo os bens mediante seu lugar na hierarquia da criação, o homem obedece e preserva a ordem natural estabelecida pelo Criador, utilizando-se do sensível para elevar-se ao inteligível. Ao mesmo tempo, fiel a esses critérios, o indivíduo também preserva a ordem social, uma vez que ama os demais de acordo com seu grau na escala dos seres, e esse amor constitui o vínculo e o princípio na cidade ou sociedade dos homens.

\section{REFERÊNCIAS BIBLIOGRÁFICAS}

AGOSTINHO, S. A cidade de Deus: Contra os pagãos, parte I. Tradução de Oscar Paes Leme. 14 ed. Petrópolis, RJ: Vozes, 2013.

AGOSTINHO, S. A cidade de Deus: Contra os pagãos, parte II. Tradução de Oscar Paes Leme. Petrópolis, RJ: Vozes, 2012.//

AGOSTINHO, S. A doutrina cristã. São Paulo: Paulus, 2002.

AgOSTINHO, S. A verdadeira religião. Tradução de Nair de Assis Oliveira. São Paulo: Paulus, 2002.

AgOSTINHO, S. A Trindade. Tradução de Augustinhu Belmonte. São Paulo: Paulus, 1995. AgOStinhO, S. A ordem. Tradução de Agustinho Belmonte. São Paulo: Paulus, 2008.

AGOSTINHO, S. Confissões. Tradução de J. Oliveira e A. Ambrósio de Pina. 6. ed. Petrópolis, RJ: Vozes, 2015.

AGOSTINHO, S. Comentário aos Gênesis. Tradução de Augustinhu Belmonte. São Paulo: Paulus, 2005.

AGOSTINHO, S. O livre arbítrio. Tradução de Nair de Assis Oliveira. São Paulo: Paulus, 1995.

AGOSTINHO, S. Retratações. Tradução de Augustinho Belmonte. São Paulo: Paulus, 2019.

AGOSTINHO, S. Primeira catequese aos não cristãos. In TRAPÊ, A. Agostinho: o homem, o pastor, o místico. Tradução de Francisco Evaristo Marcos e Marcos Roberto Nunes Costa. São Paulo: Cultor de Livros, 2018. 
FRANGIOTTI, R; OLIVEIRA, N. A. Introdução. In AGOSTINHO, S. A verdadeira religião. Tradução de Nair de Assis Oliveira. São Paulo: Paulus, 2002.

GILSON, É. Introdução ao estudo de Santo Agostinho. Tradução de Cristiane Negreiros Abbud Ayoub. 2 ed. São Paulo: Paulus, 2010.

LEÃO, E. C. Introdução. In AGOSTINHO, S. A cidade de Deus: Contra os pagãos, parte I. Tradução de Oscar Paes Leme. 14 ed. Petrópolis, RJ: Vozes, 2013.

MASCHIO, E. A. Santo Agostinho: O doutor da graça divina contra o mal. São Paulo: Editora Salvat, 2015.

ROPS, H. D. História da Igreja. Tradução Emérico da Gama. São Paulo: Quadrante, 1998.

TRAPÊ, A. Agostinho: o homem, o pastor, o místico. Tradução de Francisco Evaristo Marcos e Marcos Roberto Nunes Costa. São Paulo: Cultor de Livros, 2018. 